\title{
Evaluation of effects of exposure time on aquatic toxicity with zooplanktons using a reduced life expectancy model
}

\author{
Vibha Verma $^{\text {a**, }}$ Qiming J. Yu ${ }^{\text {a }}$, Des W. Connell ${ }^{\text {b }}$ \\ ${ }^{a}$ Griffith School of Engineering, Griffith University, Nathan Campus, Brisbane, Queensland 4111, \\ Australia \\ * Corresponding author. Tel: +617 37357186 Email address: v.verma@griffith.edu.au \\ ${ }^{\mathbf{b}}$ Griffith School of Environment, Griffith University, Nathan Campus, Brisbane, Queensland \\ 4111, Australia
}

\begin{abstract}
Traditionally in toxicological studies time is not studied as quantifiable variable but as a fixed endpoint. The Reduced Life Expectancy (RLE) model which relates exposure time and exposure concentration with lethal toxic effects was tested previously using fish data. In this current paper the effects of exposure time on aquatic toxicity with zooplanktons and various toxicants were evaluated using the RLE model based on ambient exposure concentration. The model was evaluated by plotting $\ln L T_{50}$ against $L C_{50}$ using toxicity data with zooplanktons from the literature for metal, metalloid and organic compounds. Most of the experimental data sets can be satisfactorily correlated by use of the RLE model, but deviations occurred for some data sets. Those data sets were satisfactorily fitted by a two stage RLE model. This model was based on two phases: one in the peripheral system and other in the central system. Both the single and two stage RLE model support the hypothesis that toxicity is time dependent and decreases in a systematic way with increasing exposure time. A calculated normal life expectancy (NLT) can be obtained from the single stage model and is in accord with reported NLT but those obtained from the two stage RLE model are in excellent agreement.
\end{abstract}


Key Words: Aquatic Toxicity, Effects of Exposure Time, Nonlinear Relationship, Zooplankton Toxicity, Two Stage Reduced Life Expectancy Model, Uptake Route

\section{Introduction}

During his work on acute toxicity of gases used in warfare, Haber (1924) discovered that the multiple of the exposure concentration and time produces the same biological effect e.g. lethality. Thus $\mathrm{C} \times \mathrm{t}=$ constant where $C$ is lethal exposure concentration and $t$ is exposure time. This came to be known as Haber's rule. Because of its simplicity, the relationship became a popular tool for toxicological evaluations, initially among entomologists (Miller et al., 2000). Interestingly deviations from Haber's Rule were observed, specifically noting that exposure concentration is more important than exposure duration for toxic effects to take place (Flury and Wirth, 1934). Therefore use of the rule beyond certain limits would give an incorrect relationship (Weller et al., 1999). However this simple approach has been effectively used by regulatory agencies such as USEPA as the foundation for setting the exposure limits (Atherely, 1985; Henschler, 1984).

Understanding the effects of exposure time on toxicity is important for the assessment of risks associated with the long term exposure time of humans but at a low level. This usually occurs with environmental contaminants associated with human health risks. Recently Rozman (1998) have argued that dose alone is insufficient because exposure time is an equally important factor for the occurrence of toxic effects. The fundamental significance of exposure time as a variable in toxicology has been recognised but less well understood (Witschi, 1999). Even a low level of a chemical can be toxic if the exposure time is relatively long (Yu et al., 1999). Work performed by various other researchers also indicates the importance of exposure time in toxicological studies (Zhao and Newman, 2004, 2006). 
Conventionally time is not studied as a quantifiable variable in standard toxicity testing (Rozman and Doull, 2000, 2001; Sanchez-Bayo, 2009). The traditional approach is to evaluate doseresponse relationship with time taken as a fixed endpoint only (Cairns and Mount, 1990; Forbes and Forbes, 1994; Ashauer and Escher, 2010). Chronology of the response intensity at the various doses or concentrations is seldom taken into consideration in these studies. But in the last few decades there have been several studies where exposure time is taken as quantifiable variable (Pascoe and Shazili, 1986; Hickie et al., 1995; Chaisuksaint et al., 1997; Hoang et al., 2007; Sanchez-Bayo and Goka, 2007; Beketov and Liess, 2008). By using time as a quantifiable variable, information can be obtained not only for the particular toxic dose levels but also for the exposure time (Newman and McCloskey, 1996).

In our previous study with fish (Verma et al., 2011) the RLE model was evaluated using the relationship between exposure time and the exposure lethal concentration. It was noted that irrespective of toxicant and the toxic mechanism involved the relationship between exposure time as $\ln L T_{50}$ and exposure lethal concentration $L C_{50}$ for fish was always linear. It was suggested that possibly the relationship is not a reflection of the toxic mechanism involved but more the route of toxicant uptake. However, with increasing exposure time a systematic decrease in exposure concentration was recorded. The RLE model allows the NLT to be calculated from the toxicity data. In previous work the reported NLT and calculated NLT obtained were in general accordance.

The objectives of present study were designed to evaluate the RLE Model with zooplanktons based on the toxic effects of exposure time available in the scientific literature. The characteristics obtained from evaluation of the RLE model would be used to validate the relationship of exposure time with toxicity and for estimation of effects of exposure time on life expectancy. 


\section{Theory}

\subsection{RLE Model}

The RLE model is based on a linear relationship between the internal lethal concentration of a toxicant within the organism and the corresponding exposure time. The model was developed with the use of the concept of reduction in life expectancy (Yu et al., 1999) and the model equation is given below,

$$
\operatorname{ILC}_{50}=\frac{\left(\operatorname{lnNLT} T_{50}-\operatorname{lnLT} T_{50}\right)}{\mathrm{d}}
$$

Where $I L C_{50}$ is the internal lethal concentration, $L T_{50}$ is the exposure time, $N L T_{50}$ is the normal life expectancy of the organism and $d$ is a constant.

But due to the limited availability of $I L C_{50}$ data in the scientific literature, relationship was extended from using the internal concentration to using the external concentration. Based on this extension a new model was proposed (Connell and $\mathrm{Yu}, 2008$ ) which can be described by the equation given below:

$$
\mathrm{LC}_{50}=\frac{\left(\operatorname{lnNLT} \mathrm{T}_{50}-\operatorname{lnLT} \mathrm{T}_{50}\right)}{\mathrm{d}}
$$

or,

$$
\mathrm{LC}_{50}=-\mathrm{a} \operatorname{lnLT} \mathrm{T}_{50}+\mathrm{b}
$$

where $L C_{50}$ is external lethal concentration, $a$ is $-1 / d$ and $b$ is $l n N L T_{50} d d$.

According to the RLE model, when $L C_{50}$ is zero the organism will have a normal life expectancy and it is related to the model constants as follows, 


$$
N L T_{50}=\frac{b}{a}
$$

\subsection{A Two Stage RLE Model}

The RLE model is based on the concept that there is a linear relationship between exposure time period $\left(\ln L T_{50}\right)$ and concentration $\left(L C_{50}\right)$. However, it was observed in this study that some data sets exhibit nonlinear characteristics. Nonlinear relationships between $\log \mathrm{LT}_{50}$ and $\log \mathrm{LC}_{50}$ have also been noticed (Bliss 1940; Wuhrmann, 1952; Herbert, 1965; Zhao and Newman, 2006) at low concentrations and longer exposure durations. At higher concentrations and shorter exposure durations, this relationship is usually linear (Naddy et al., 2000). In order to correlate this nonlinearity observed in some data set, here it is proposed that the data set is divided into two segments at different exposure time periods, and each of the segments can be correlated with the linear RLE model. The original RLE model is referred as the single stage RLE model and the new model as the two stage RLE model. The equation of the single stage RLE model (Equation 3) is applied individually for each segment of the two stage RLE model. This can be illustrated with a conceptual diagram (Figure 1) where the solid line represents the original RLE model (single stage RLE model) and the two broken lines represent the two stage RLE model. These two broken lines converge at a common end point where a change in slope takes place. The first stage in the diagram has a higher slope and the second stage has a relatively lower slope.

The concept underlying the development of the single stage and the two stage model is the single compartment approach where a single compartment is used to represent an organism (Moriarty, 1975; Connell, 1990). When the organism is exposed to a toxicant, it penetrates the organism body, enters into the peripheral system and then gets distributed in the entire body of the organism. Exchange processes like elimination and degradation are the dominant processes in the

peripheral system. Because of these dilution processes and movement of toxicant as it is 
distributed in the entire body of organism towards the target site, the concentration of the toxicant cannot increase beyond a certain level. Thus toxicant accumulation in the peripheral system does not reach a threshold level. The toxicant resulting from the dilution processes in the peripheral system of the organism body reaches to the central system and it starts accumulating there. Once the concentration of the toxicant in the central system reaches to a threshold level, toxic effects (mortality or some other toxicity endpoint) are observed (Mancini, 1983).

The first stage of the two stage model corresponds to the processes in the peripheral system at the earlier phase of the exposure to toxicant and the second stage of model represents the second phase of the exposure processes. The processes in the first phase occur at faster paces while the processes taking place in the second phase occur at considerably slower paces. In general when the overall relationship obtained is linear, first and second stages cannot be distinguished from each other. In this case a single stage model can be used to describe the toxicity. However in the situation where relationship observed is nonlinear, both first and second stages can be distinguished due to a changing slope at the common end point.

\section{Methodology}

\subsection{Organisms and Toxicants Selected for Evaluations}

Zooplanktons were selected as organisms for this study since plenty of toxicity data related to this group are available. Zooplanktons are key components of both marine and freshwater food web as they are the primary grazers in several ecosystems and serve as a main source of food for developing larvae and fish (Hook and Fisher, 2001). Thus zooplanktons have a key role to play in the trophic structure of aquatic ecosystems, vital for energy transfer at secondary level between the autotrophs and the heterotrophs (Deivanai et al., 2004; Kanagasabapathi and Rajan, 2010). It would be interesting to evaluate the effects of exposure time on such a key component of aquatic 
systems. Microscopic crustacean, ostracods (Cypridopsis vidua and Stenocyris major), copepods (Arctodiaptomus salinus and Mesocyclops lueckarti), cladoceran (Daphnia magna) and small millimetresized amphipods (Gammarus pulex, Gammarus lacustris and Gammarus psuedolimnaeus) are the organisms selected for study.

Toxicants having significantly different toxic mechanism are selected for this study and they included toxic metals $(\mathrm{Cu}, \mathrm{Zn}, \mathrm{Pb}, \mathrm{Ni}, \mathrm{Fe}, \mathrm{Mn}, \mathrm{Al}$ and $\mathrm{Cd})$, a metalloid $(\mathrm{Se})$ and organic compounds (imidacloprid, thialcoprid, lindane, fenvalerate, flucythrinate, BHC, fudaran and dimethoate). Among these toxicants, $\mathrm{Pb}, \mathrm{Cd}$, Ni has no known biological significance while $\mathrm{Cu}$, $\mathrm{Zn}, \mathrm{Fe}, \mathrm{Mn}$ and Se are biologically important. Organic compounds selected for study are mainly pesticides and those have no known biological significance. Among these toxicants metals and metalloids enter the environment through both natural and human activities but presence of organic compounds is entirely consequences of human activities.

\subsection{Sources and Collection of Data}

Toxicity data related to zooplanktons with these particular groups of toxicants were obtained from the scientific literature. These data sets include information about change in $L C_{50}$ against varying exposure durations with zooplanktons. The data obtained from the literature are in various units for concentration such as $\mathrm{mg} / \mathrm{L}, \mathrm{g} / \mathrm{L}$, ppm or $\mathrm{ppb}$. For consistency all units were converted into $\mu g / L$. Similarly exposure time period was also expressed in various units (hours, minutes and seconds) of time and all were converted into days $(d)$. The NLT data of each organism was also obtained from scientific literature. But the NLT of ostracod S.major and copepod A.salinus is not available in the literature. The temperature of the ambient water used as the medium to conduct the experiments from where toxicity data are obtained ranged between $13{ }^{\circ} \mathrm{C}$ to $30{ }^{\circ} \mathrm{C}$. 


\subsection{Processing of Data}

The data sets for each zooplankton species were used to evaluate the relationship between $L C_{50}$ and $\ln L T_{50}$ with the RLE Model expressed in Equation 3. Thus $L C_{50}$ was plotted against $\ln L T_{50}$ and linear regression analysis was used to obtain the regression equation and the correlation coefficient $\left(R^{2}\right)$ using Excel. The values of the slope $(a)$ and intercept $(b)$ were obtained from the regression equation. These values were then used to obtain the calculated NLT of each organism by the use of Equation 4.

All the data sets were correlated by using the single stage RLE model first. It was noted that most of the plots followed the single stage RLE model well. However some plots had regression coefficient value less than 0.8 . For those, plots based on the two stage model were obtained. Firstly, each data set was divided into two subsets, in such a way that two separate linear segments appear converging at a common endpoint where the slope of the relationship changes sharply. These plots resemble the conceptual diagram in Figure 1. In the situation when numbers of data points in a data set are limited, a few points were used as common points in both segments, such that there was enough data to obtain two linear regression lines. The regression line with the higher slope corresponds to the peripheral system and it was referred as Stage-1 (S-1). The other line with a lower slope corresponds to the central system and referred as Stage-2 (S-2). The values of $a$ and $b$ were obtained from the regression equations for each segment and then $N L T_{50}$ was calculated from S-2 using Equation 4.

\section{Results and Discussions}

\subsection{Relationship of Exposure Time to Toxicity}

The plots of $\ln L T_{50}$ against $L C_{50}$ based on Equation 3 are shown in Figures 2- 4. These plots utilise data from the literature (Table1) on zooplanktons for lethal effects as a result of exposure to 
toxicants over time. Plots for the metalloid and metals are shown in Figure 2 a-e and the corresponding plots for pesticides are shown in Figure 3 a-d. With data sets where correlation coefficient was less than 0.8, two stage plots were obtained (see Section 3.3). Plots corresponding to the two stage model are shown in Figure 4 a- d. This occurred with four data sets out of a total of twenty five sets.

The characteristics of the relationships established using the regression equation can be used to compare the toxic effects of the metals, the metalloid and the pesticides (Table 1). The slopes of the regression equations reflect the strength of the toxic effects on the various zooplanktons. Though on average the slope is approximately same for both groups, the metals exposure differs to that observed with the pesticides. Since the range of slopes obtained for the metals and metalloid is from -0.08 to $-25,000$ while for the pesticides the range is from -0.07 to $-11,000$. The range is comparatively wider for the group of metals and the metalloid than for pesticides. This is also apparent from the ratio of the average of the slopes with pesticides to metals which is $-2,000 /$ $-2,800$ while the ratio of the standard deviations with pesticides to metals is $3,300 / 6,500$. Different toxic mechanisms involved with metals and pesticides may be responsible for this difference.

A comparison of these results with those obtained from previous paper with fish listed in Table 3 (Verma et al., 2011) indicates that though slopes obtained from regression analysis are negative but fish has much wider range $(-0.420$ to $-210,000)$ with excellent $R^{2}(0.830$ to 0.999$)$ than zooplanktons having $R^{2}$ value between 0.571 to 0.994 and slope range between -0.07 to $-25,000$. When slope obtained are compared for individual groups of toxicants, ratio of average for fish to metals and zooplanktons to metals is $-13,300 /-2,800$ and ratio of standard deviation for these groups is $-13,700 /-6,500$ respectively. For fish with metals, both average and standard deviation of slope is much higher than zooplanktons with metal. Similar pattern is repeated when ratio of 
average for fish to pesticides and zooplanktons to pesticides are compared which is $-33,000 /-2,900$ and standard deviation ratio is $68,000 / 4,000$ respectively. Here over all ratio of the average of the slopes obtained for fish to all toxicants with zooplanktons to all toxicant is $-21,000 /-5,500$ with standard deviation ratio of 44,000/2,800 respectively. Overall trend obtained for all toxicants with fish and zooplanktons is that the ratio of average and standard deviations for fish is higher than zooplanktons.

All the regression relationships have negative slopes (see Table 1) ranging from -0.07 to $-25,000$ which indicates that the toxicity is related to the exposure time and declines as the exposure time increases. These results are in accord with the results obtained by Landrum et al. (2005) who were studying the time dependent toxicity of dichlorodiphenyldichloroethylene to Hyallea azteca. Also Kurve et al., (2010) reported that toxicity is inversely proportional to exposure time when comparing the toxicity of pesticides, BHC with fudaran. Various other researchers also reached the same conclusion while studying the toxicity of fenvalerate to amphipod (G.psuedolimaneus) and various metals to copepod (S.major) respectively (Anderson, 1982; Shuhaimi-Othman et al., 2011).

In zooplanktons the routes of toxicants uptake are from outer body surface, gills and food. But due to smaller body size the most effective route of toxicant uptake is diffusion through outer body surface which is thin (Pirow et al., 2004). Uptake of toxicant takes place in fish principally through diffusion via gills but in the relatively small sized zooplanktons, diffusion is through outer body surface. In fact diffusion is effectively operational for only a short distance, thus it can be related to transport through relatively thin physical barriers such as respiratory surfaces and internal tissues (Pirow et al., 2004). Relatively very small zooplanktons with smaller volume and a 
larger surface area are ideal for this process to be operational. But in larger aquatic animals such as fish, ventilatory and circulatory convection is the effective process (Shelton, 1992).

The relationship of $L C_{50}$ and $\ln L T_{50}$ is linear for most of the zooplankton plots obtained, with high correlation coefficients ranging from 0.815 to 0.994 (Figures 2 a- e and Figures 3 a-d) irrespective of whether the particular toxicant is a metal or a pesticide. But some of the plots have nonlinear relationship with correlation coefficients ranging from 0.571 to 0.758 , belonging to both groups of toxicants. Thus a linear or nonlinear relationship between $L C_{50}$ and $\ln L T_{50}$ does not characterise to any particular group of toxicants. Previous work also supports the occurrence of both linear and nonlinear relationship among zooplanktons e.g. Gause (1932) obtained nonlinear relationship on logarithmic scale using the data published by Hartmann (1918) who studied toxicity of mercuric chloride on crustaceans (Belonostomus longirostris). Interestingly a study on toxicity of mercuric chloride with crustacean (Simocephalus) also reached to same conclusion (Breukelman, 1932). Bliss (1940) worked on the data obtained from Alison (1928) based on toxicity of hydrocyanic acid with cockroach and supported the occurrence of a nonlinear relationship. Though, he stated that the nonlinear relationship is not very common. While Yu et al. (1999) observed linear relationship from their study using the data obtained from the literature on chlorobenzenes with crabs (Portunus pelagicus).

\subsection{Nonlinear Relationship: Application of Two Stage Model}

Data sets which do not have a linear relationship i.e. $R^{2}<0.8$ were replotted in Figure 4, using two stage model. The total number of plots of toxicity data made in this work was 25 and from this 14 are with metal data, 1 metalloid data and 10 pesticide data. However there are only four plots out

of this 25 which had a nonlinear relationship i.e. $R^{2}<0.8$. Interestingly out of these four plots only 1 belongs to the metal group though it is a comparatively larger group with 14 data sets in total. 
The remaining 3 plots are of pesticides data having 10 datasets in total. This makes the two stage relationship more common among the organism exposed to pesticides than metals and metalloid. The characteristics of the relationship obtained using the regression equations obtained from two stage RLE model can be used to compare the toxic effects of datasets having nonlinear relationships (Table 2). It is suggested that S-1 takes place in peripheral system at faster rate while S-2 takes place in central system at a slower rate depending upon the mode of toxic action. When only one mode of action dominates then S-1 and S-2 cannot be differentiated and a linear relationship is observed. But when a particular toxicant has more than one mode of toxic action, one in the peripheral system and other in the central system then a nonlinear relationship is observed.

According to Gause (1932) and Bliss (1940), it is not usual for a toxicant to act upon an organism in several different modes. These authors concluded that up to a certain range of toxicant concentration one mode of action is operational but replaced by another with an increase in concentration. Later on Miller et al., (2000) suggested a nonlinear relationship was a result of involvement of more than one mode of toxic action which depends upon length of exposure duration and exposure concentration.

The correlation coefficients obtained for S-1 are in the range of $0.727-0.999$ and for S-2 in the range of $0.843-0.999$ indicating an excellent linear relationship with S-2 which corresponds to the central system. A negative linear relationship in this stage indicates that toxicity is related to exposure time and decreases with increasing exposure time and is independent of a change in mode of toxic action. 
The slopes obtained from the two stage model for S-1 range from -700 to $-28,000$ while $\mathrm{S}-2$ is much less at -40 to -600 . Ratio of the average of slopes obtained for $S-1$ to $S-2$ is $-8500 /-280$ and ratio of the standard deviation obtained is $13,000 / 280$. This confirms that the processes in the first phase occur at faster rate and slow down after entering the second phase.

\subsection{Comparison of the Reported NLT with Calculated NLT}

Several sources of error have been recognised in carrying out a comparison of the reported NLT with that calculated from the relationship of Equation 4 to derive the NLT. The most important source of error is the age of the zooplankton before exposure to toxicant since it is usually unknown. In addition another factor influencing these results is the procedure for making a decision on death during the toxicity test. Normally zooplanktons exposed to toxicant are considered dead during the experiment, once they are immobile but sometimes immobility can be due to stress or unconsciousness while animal is still physiologically alive (Seepersad et al., 2004). These facts can lead to errors in the toxicity data which can flow onto errors in the NLT calculated by extrapolation of this toxicity data.

The reported NLT was compared with calculated NLT and in most cases the calculated NLT differs from the reported NLT (Table 1). Interestingly calculated NLT of D. magna with Zn, Cu, Cd and imidacloprid is longer than reported NLT.

In comparison of the reported NLT with calculated NLT the characteristics of the relationship established using the regression equations have been used (Table 1). The reported NLT and calculated NLT are in the range of $30-500 \mathrm{~d}$ and $2-260 \mathrm{~d}$ respectively. The ratio of averages of the reported NLT and the calculated NLT is $240 / 50$ and the ratio of the standard deviation is 200/80. On a theoretical basis these ratios should be approximately the same, but the results are in 
general accordance. The coefficient obtained from the plots of reported NLT against calculated NLT is low (0.430) and the P-value obtained from the Student's t-test, is 0.017 which also denotes that the results are in a general accord.

The ratios of averages and standard deviations calculated for both reported NLT and calculated NLT with fish from previous paper are compared with those obtained with zooplanktons from the present work. The ratio of average reported NLT for all toxicants with fish to zooplanktons is $1300 / 240$ and standard deviation is $800 / 200$ respectively. While the ratio of average calculated NLT for all toxicants with fish to zooplanktons is $260 / 50$ and standard deviation is $1100 / 80$ respectively. The ratio of $\mathrm{R}^{2}$ obtained from plotting reported NLT against calculated NLT with fish to zooplanktons is $0.262 / 0.431$ and the P-value obtained from the Student's t-test is 0.003/0.017 respectively.

The calculated NLT obtained for S-1 and S-2 ranges from 1 to 25 and 5 to 620 respectively. But the ratio of the average obtained for reported and calculated NLT from S-1 is 290/10 and standard deviation is $210 / 10$, having approximately 20 to 30 -fold difference. The poor correlation coefficient (0.431) obtained for the ratio between two is an indication that the relationship is not in harmony with the RLE model. On the other hand the ratio of the average obtained for reported and calculated NLT from S-2 is $290 / 280$ and the standard deviation is $210 / 290$ with a correlation coefficient of 0.925 and P-value obtained from Student's t test of 0.954. Thus this indicates an excellent agreement between reported and calculated NLT for S-2.

Several discrepancies regarding the reporting of the NLT of zooplankton were also noticed. For example the reported NLT for D. magna (cladoceran) is on average $60 \mathrm{~d}$ (Van Leeuwan et al., 1987) but according to Euent et al., (2008) NLT of the female is $105 \mathrm{~d}$ and the male is $48 \mathrm{~d}$. It is 
important to note that some have reported that the NLT of D. magna varies with temperature e.g. $40 \mathrm{~d}$ at $25{ }^{\circ} \mathrm{C}, 60 \mathrm{~d}$ at $20{ }^{\circ} \mathrm{C}$ (Jonczyk and Gilron, 2005) and $80 \mathrm{~d}$ at $14{ }^{\circ} \mathrm{C}$ (Korpelianen, 1986). Hoang et al. (2007) and Sanchez-Bayo (2009) have mentioned that D. magna exposed to toxicants lived longer than its reported NLT during the experiment. Particularly Hoang et al., (2007) reported $L T_{50}$ for D. magna exposed to zinc $(59 \mu \mathrm{g} / \mathrm{L})$ at $160 \mathrm{~d}$ and Sanchez-Bayo (2009) reported $L T_{50}$ for D. magna exposed to imidacloprid $(250 \mu \mathrm{g} / \mathrm{L})$ was $380 \mathrm{~d}$.

Interestingly the NLT of M.leuckarti (copepod) also changes with temperature in similar pattern which is $120 \mathrm{~d}$ at $10{ }^{\circ} \mathrm{C}, 58 \mathrm{~d}$ at $15{ }^{\circ} \mathrm{C}, 45 \mathrm{~d}$ at $20{ }^{\circ} \mathrm{C}$ and $32 \mathrm{~d}$ at $25{ }^{\circ} \mathrm{C}$ (Vijvenberg, 1980). While Gophen (1976) reported the NLT of male and female are different at different temperatures so that at $27{ }^{\circ} \mathrm{C}$ the male NLT is $8 \pm 4 \mathrm{~d}$ while the female NLT is $42 \pm 19 \mathrm{~d}$. G. pulex has a reported NLT of 12 months (Nilsson, 1977; Sutcliffe et al., 1981), while according to Mortensen (1982) the NLT is 2 yrs. Welton and Clark (1980) have reported that female and male G. pulex have different NLT which are 17 - 23 months and 2 - 5 yrs respectively.

This reflects the difficulties in establishing NLT which is normally not the primary objective of the various research group but rather a secondary objective. Apparently the NLT of these zooplanktons is temperature dependent. In general reduced temperature leads to a reduced metabolic rate, oxygen consumption, respiration and growth rate, resulting in an increased NLT (Korpelaianen; 1986; Paul et al., 1997). Later supported by Lampert et al. (2010) who argued longevity is enhanced at low temperature due to reduced metabolism. Thus a decrease in temperature of the ambient water decreases the metabolism of organism which results in longer NLT. The toxicity data used in this study are obtained from various sources from experiments carried out in water with temperatures ranging from $13-30{ }^{\circ} \mathrm{C}$. Thus the NLT of zooplankton at $13{ }^{\circ} \mathrm{C}$ temperature can increase test organism's NLT while $30{ }^{\circ} \mathrm{C}$ can reduce the NLT. 


\subsection{Conclusions}

The relationship between $\ln L T_{50}$ and $L C_{50}$ using the single stage RLE model with 21 sets of the zooplankton data is linear but nonlinear with four sets. Thus with most species and toxicants it has the competence to effectively relate effects of exposure time and exposure concentration to toxic effects using a linear RLE model. Additionally, the two stage RLE model has been applied and gives an approximation of the relationship of exposure time with exposure concentration to describe the toxicity when the relationship is nonlinear.

Thus zooplanktons exhibit both linear and nonlinear relationships. In both situations slopes obtained are negative, similar to the slopes obtained with fish. Thus toxicity is function of exposure time and decreases in an orderly pattern with increasing exposure time. There are differences in the slopes of these relationships which suggests that groups of toxicants chosen for study ranging from metal ions to organic compounds have different toxic mechanisms. These conclusions are in excellent harmony with the results obtained for fish. Interestingly the calculated NLT obtained from RLE model is found to be different from reported NLT in most cases. However the calculated NLT obtained from the two stage model for S-2 which is the dominant phase of nonlinear relationship, is in excellent agreement with reported NLT.

The results obtained from evaluation of toxicity data with the zooplankton are in excellent agreement with those obtained for fish described in our previous paper but with one exception. The relationship is linear with excellent correlation coefficient for fish while both linear and nonlinear relationship is observed with zooplanktons.

\section{References:}


Abel P.D., 1980. Toxicity of $\Upsilon$-hexaclorocyclohexane (lindane) to Gammarus pulex: mortality in relation to concentration and duration of exposure. Freshwat Biol. 10, 251-259.

Alison , J.B., 1928. Studies on the toxicity of hydrocyanic acid. Ia. State. Col. J. Sci. 2, 243-252.

Anderson, R.L., 1982. Toxicity of fenvalerate and permathrin to several nontarget aquatic invertebrates. Environ. Entomol. 11, 1251-1257.

Anderson, R.L., 1984. Toxicity of flucythrinate to Gammarus lacustris (amphipoda), Pteronarcys dorsata (plecoptera) and Brachycentrus americanus (trichoptera): Importance of exposure duration. Environ. Poll. (Series A) 35, 353-365.

Ashauer, R., Escher, B., 2010. Advantages of toxicokinetic and toxicodynamic modelling in aquatic ecotoxicology and risk assessment. J. Environ. Monit. 12, 2056-2061.

Atherely G., 1985. A critical review of time-weighted average as an index of exposure and dose, and of its key elements. Am. Ind. Hyg. Assoc. J. 46, 481-487.

Beketov, M.A., Liess, M., 2008. Acute and delayed effects of neonictinoid insecticide thialcoprid on seven freshwater arthropods. Environ. Toxicol. Chem. 27, 461-470.

Bliss, C.I., 1940. The relation between exposure time, concentration and toxicity in experiments on insecticide. Ann. Entomol. Soc. Am. 33, 721-766.

Bonnomet, V., Duboudin, C., Magaud, H., Thybaud, E., Vindimian E., Beauzamy B., 2002. Modelling explicitly and mechanistically median lethal concentration as a function of time for risk assessment. Environ. Toxicol. Chem. 21, 2252-2259.

Bousfield, E.L., 1958. Freshwater amphipod crustaceans of glaciated Noth America. Can. Field Nat. 72, 55-113.

Breukelman, J., 1932. Speed of toxic action of mercuric chloride on daphnids. Physiol. Zool. 5, 207-217.

Cairns, J., Mount, D.I., 1990. Aquatic toxicology. Environ. Sci. Technol. 24, 154-161.

Chaisuksiant, Y., 1999. Bioconcentration and Toxic Effects of Halobenzenes with Fish. Ph D thesis, Faculty of Environmental Sciences, Griffith University, QLD, Australia.

Connell, D.W., 1990. The octanol-water partition coefficient. In: Carlow P., (Ed.), Handbbook of Ecotoxicology. Vol. 2, Blackwell, Oxford, pp 320-322.

Connell, D.W., Yu, J., 2008. Use of exposure time and life expectancy in models for toxicity to aquatic organisms. Mar. Poll. Bull. 57, 245-249.

Deivanai, K.S., Arunprasanth, Rajan, M.K., Baskaran, S., 2004. Biodiversity of phyto and zooplankton in relation to water quality parameters in a sewage polluted pond at Ellayirampannai, Virudhnaga District. In: The Proceedings of National Symposium on Biodiversity Resources Management and Sustainable use, organised by the centre for biodiversity and forest studies, Madurai Kamaraj University, Madurai. 
Euent, S., Menzel, R., Steinberg, C.E.W., 2008. Gender-specific lifespan modulation in Daphnia magna by a dissolved humic substances preparation. Ann. Environ. Sci. 2, 7-10

Flury, F., Wirth, W., 1934. Zur Toxikologie der Losungsmitted (verschiedene Ester, Aceton, Methylalkohol). Arch. Gewerbepath. Gewerbehyg. 5, 2-90.

Forbes, T.L., Forbes, V.E., 1993. A critique of the use of distribution based extrapolation methods in ecotoxicology. Funct. Ecol. 7, 249-254.

Gause, G.F., 1932. Certain properties of the curves of toxicity. Protoplasma 17, 548-553.

Gophen, M., 1976. Temperature effect on lifespan, metabolism and development time of Mesocyclops leuckarti (Claus). Oeceologia 25, 271-277.

Haber, F., 1924. Zur geschichte des gaskrieges (On the history of gas warfare). In: Funf Vortrage aus den Jahren 1920-1923 (Five Lectures from the years 1920-1923). Springer, Berlin, pp 75-92.

Hartmann, O., 1918. Fiir die gesmte physiolgie des menschen und die tiere. Pflugers Arch. 170, 585-645.

Hickie, B.E., McCarty, L.S., Dixon, D.G. 1995. A residue-based toxicokinetic model for pulse exposure toxicity in aquatic systems. Environ. Toxicol. Chem. 14: 2187-2197.

Herbert, D.W.M., 1965. Pollution and fisheries. Ecol. Ind. Soc., 5th Symp. British Ecol. Soc. 173195. Blackwell Scientific, Oxford.

Henschler, D., 1984. Exposure limits: history, philosophy, future developments. Ann Occup. Hyg. 28, 79-92.

Hoang, T.C., Tomasso, J.R., Klaine, S.J., 2007. An integrated model describing the toxic responses of Daphnia magna to pulsed exposures of three metals. Environ. Toxicol. Chem. 26, 132-138.

Hook, S.E., Fisher, N.S., 2001. Sublethal effects of silver in zooplankton: importance of exposure pathways and implications for toxicity testing. Environ. Toxicol. Chem. 20, 568-574.

Jonczyk, E., Girlon, G., 2005. Acute and chronic toxicity testing with Daphnia sp. In: Blaise, C., Ferard, J. (Eds.), Small Scale Freshwater Toxicity Investigations: Toxicity Test Methods, Vol. 1, Springer, Dordrecht, The Netherlands, pp 337-393.

Kanagasabapathi, V., Rajan, M.K., 2010. A preliminary survey of plankton in Irrukkangudi reservoir, Virudhnagar district, T.N., India. J. Phytol. 2, 63-72.

Kooijman, S.A.L.M., 1981. Parametric analysis of mortality rates in bioassys. Wat. Res. 15, 107119.

Korpelainen, H., 1986b. The effects of temperature and photoperiod on life history parameters of Daphnia magna (Crustacea: Cladocera). Freshwat. Biol.16, 615-620. 
Kurve, P.N., Kulkarni, G.V., Phal, K.D., 2010. Comparative study of acute toxicity of BHC and fudaran on Mesocyclops leuckarti (Claus 1857) by LC Ln $_{50}$ analysis. Adv. Biores. 1, 131-138.

Landrum, P.F., Steevens, J.A., McElroy, M., Gossiux, D.C., Lewis, J.S., Robinson, D.C., Lewis, J.S., Robinson, S.D., 2005. Time dependent toxicity of dichlorodiphenyldichloro- ethylene to Hyallea azteca. Environ. Toxicol. Chem. 24, 211-218.

Lampert, W., Lampert, K.P., Larsson, P., 2010. Coexisting overwintering strategies in Daphnia pulex: a test of genetic differences and growth responses. Limnol. Oceanogr. 55, 18931900.

Mancini, J.L., 1983. A method for calculating effects, on aquatic organisms, of time varying concentrations. Wat. Res. 17, 1355-1362.

McCahon, C.P., Pascoe, D., 1988. Cadmium toxicity to the freshwater amphipod Gammarus pulex (L.) during the moult cycle. Freshwat. Biol. 19, 197-203.

Miller, F.J., Schlosser, P.M., Janszen, D.B., 2000. Haber's Rule: a special case in a family of curves relating concentration and duration of exposure to a fixed level of response for a given endpoint. Toxicology. 149, 21-34.

Moriarty. F., 1975. Exposure and residues. In: Moriarty F., (Ed.), Organochlorine Insecticides: Persistent Organic Pollutants. Academic Press, London, pp29-72.

Mortensen, E., 1982. Production of Gammarus pulex L. (amphipoda) in small Danish stream. Hydrobiologia 87, 77-97.

Naddy, R.B., Johnson, K.A., Klaine, S.J., 2000. Response of Daphnia magna to pulsed exposures of chlorpyrifos. Environ. Toxicol. Chem. 19, 423-431.

Newman, M.C., McCloskey, J.T., 1996. Time-to-event analyses of ecotoxicity data. Ecotoxicology 5,187-196.

Nilsson, L.M., 1977. Incubation time, growth and mortality of the amphipod Gammarus pulex under laboratory conditions. Biol. Sci. 29, 93-98.

Pascoe, D., Shazili, N.A.M., 1986. Episodic pollution- a comparison of brief and continuous exposure of rainbow trout to cadmium. Ecotoxicol. Environ. Saf. 12: 198-198.

Parra, G., Guerrero, F., Jimenez-Melero, R., 2005. Agricultural impacts on Mediterranean wetlands: the effect of pesticides on survival and hatching rates in copepods. Am. Lomnol. Int. J. Lim. 41, 161-167.

Paul, R.J., Colmorgen, M., Pirow, R., Chen, Y.H., Tsai, M.C., 1997. Circulation and respiratory control in millimetre-sized animals (Daphnia magna, Folsomia candida) studied by optical methods. J. Comp. Physiol. B 167, 399-408. 
Pirow, R., Baumer, C., Paul, R.J., 2004. Crater landscape: two-dimensional oxygen gradients in the circulatory system of the microcrustacean Daphnia magna. J. Exper. Biol. 207, 43934405 .

Rozman, K.K., 1998. Quantitative definition of toxicity: a mathematical description of life and death with dose and time as variables. Med. Hypothese 51, 175-178.

Rozman, K.K., Doull, J., 2000. Dose and time as variable of toxicity. Toxicology 144, 169-178.

Rozman, K.K., Doull, J., 2001. The role of time as a quantifiable variable of toxicity and the experimental conditions when Haber's $\mathrm{C} \times \mathrm{t}$ product can be observed: implications for therapeutics. J. Pharmacol. Exp. Therap. 296, 663-668.

Sanchez-Bayo, F., 2009. From simple toxicological model to prediction of toxic effect in time. Ecotoxicology 18, 343-354.

Sanchez-Bayo, F., Goka, K., 2007. Simplified models to analyse time and dose dependent responses of populations to toxicants. Ecotoxicology 16, 511-523.

Seepersad, B., Ramnath, K., Dyal, S., 2004. The use of aniline blue for the determination of dead phytoplankton, zooplankton, meroplankton in $\mathrm{LC}_{50}$ testing after $96 \mathrm{hr}$ - a re-evaluation of the US Environmental Protection Agency methodology. J. Ene. Res. Technol. 126, 215219.

Shelton, G., 1992. Model applications in respiratory physiology. In: Egginton, S., Ross, H.F. (Eds), Oxygen Transport in Biological Systems, vol. 51, SEB seminar series Cambridge University Press, Cambridge, pp. 1-44.

Shuhaimi-Othman, M., Nadzifah, Y., Ramle, N., Ahmad, A.K., 2011. Toxicity of metals to a freshwater ostracod: Stenocyris major. J. Toxicool. Article ID: 136104, doi: $10.1155 / 2011 / 136104$.

Sutcliffe, D.W., Carrick, T.R., Willoughby, L.G., 1981. Effects of diet, body, size, age and temperature on growth rates in the amphipod Gammarus pulex. Freshwat. Biol. 11, 183214.

Van Leeuwen, C.J., Niebeek, G., Rijkeboer, M., 1987. Effects of chemical stress on the population dynamics of Daphnia magna: A comparison of two test procedure. Ecotoxicol. Environ. Saf. 14, 1-11.

Verma, V., Yu, Q.J., Connell, D.W., 2011. Use of reduced life expectancy model for evaluation of effects of exposure time on aquatic toxicity. $15^{\text {th }}$ International Symposium on Toxicity Assessment, Hong Kong.

Vijvenberg, J., 1980. Effect of temperature in laboratory studies on development and growth of Cladocera and Copepoda from Tjieuremeer, The Netherlands. Freshwat. Biol. 10, 317-340.

Weller, E., Long, N., Smith, A., Williams, P., Ravi, S., Gill, J., Henessey, R., Skornik, W., Kimmel, C., Kimmel, G., Holmes, L., Ryan, L., 1999. Dose-rate effects of ethylene oxide exposure on developmental toxicity. Toxicol. Sci. 50, 259-270. 
Welton, J.S., Clarke, R.T., 1980. Laboratory studies on the reproduction and growth of the amphipod, Gammarus pulex (L.). J. Anim. Ecol. 49, 581-592.

Witschi, H., 1999. Some notes on the history of Haber's law. Toxicol. Sci. 50, 16-168.

Wudkevich, K., Wisenden, B.D., Douglas, P.C., Smith, R.J.F., 1997. Reactions of Gammarus lacustris to Chemical stimuli from natural predators and injured conspecifics. J. Chem. Ecol. 23, 1163-1173.

Wuhrmann, K., 1952. Sur quelques principes de la toxicology du poisson. (Concerning some principles of toxicology of fish. J. Bull. Centre belge d'Etude et de Documentation des Eaux, No.15, pp. 49. (Fish Res. Bd. Canada, Translation series, No.243.)

Yu, Q., Chaisuksant, Y., Connell, D.W., 1999. A model for non-specific toxicity with aquatic organisms over relatively long period of exposure time. Chemosphere 38, 909-918.

Zhao, Y., Newman, M.C., 2004. Shortcomings of the laboratory derived median lethal concentration for predicting mortality in field populations: Exposure duration and latent mortality. Environ. Toxicol. Chem. 23, 2147- 2153.

Zhao, Y., Newman, M.C., 2006. Effects of exposure duration and recovery time during pulsed exposures. Environ. Toxicol. Chem. 25, 1298-1304. 
Table 1: Regression analysis of zooplanktons toxicity data for metals, metalloid and pesticides from the literature

\begin{tabular}{|c|c|c|c|c|}
\hline Zooplanktons \&Toxicants & $\begin{array}{l}\text { Reported* } \\
\text { NLT(days) }\end{array}$ & $\begin{array}{c}\text { Calculated } \\
\text { NLT (days) }\end{array}$ & $\begin{array}{l}\text { Slope } \\
\text { (a) }\end{array}$ & $\begin{array}{l}\text { Regression } \\
\text { Coefficient } \\
\left(\mathbf{R}^{2}\right)\end{array}$ \\
\hline $\begin{array}{l}\quad \text { Single Stage Model } \\
\quad \text { Zooplanktons - Metals } \\
\text { D.magna }-\mathrm{Zn} \\
\begin{array}{l}\text { D.magna }-\mathrm{Cu} \\
\text { (Hoang et al., 2007) }\end{array}\end{array}$ & $\begin{array}{c}\text { Avg. } 60 \\
\text { (Korpelianen, } \\
1986)\end{array}$ & $\begin{array}{l}160 \\
260\end{array}$ & $\begin{array}{l}-110 \\
-10\end{array}$ & $\begin{array}{l}0.704 \\
0.862\end{array}$ \\
\hline $\begin{array}{l}\text { D.magna - Cd as } \mathrm{CdCl}_{2} \\
\text { (Kooijman (1981) }\end{array}$ & & 160 & -10 & 0.840 \\
\hline $\begin{array}{l}\text { G.pulex - Cd as } \mathrm{CdCl}_{2} \cdot 2 \frac{1}{2} \mathrm{H}_{2} \mathrm{O}(\mathrm{I}) \\
\text { G.pulex }-\mathrm{Cd} \text { as } \mathrm{CdCl}_{2} \cdot 2 \frac{1}{2} \mathrm{H}_{2} \mathrm{O}(\mathrm{P}) \\
\text { (McCohan \& Pascoe, 1988) }\end{array}$ & $\begin{array}{c}400 \\
\text { (Nilsson, 1977) }\end{array}$ & $\begin{array}{l}4 \\
4\end{array}$ & $\begin{array}{r}-200 \\
-80\end{array}$ & $\begin{array}{l}0.873 \\
0.931\end{array}$ \\
\hline $\begin{array}{l}\text { A.salinus }-\mathrm{Cu}^{* *} \\
(\text { Parra et al., 2005) }\end{array}$ & & 4 & -0.8 & 0.994 \\
\hline S.major $-\mathrm{Cu}$ as $\mathrm{CuSO}_{4} .5 \mathrm{H}_{2} \mathrm{O}^{* *}$ & & 6 & -40 & 0.926 \\
\hline S.major $-\mathrm{Cd}$ as $\mathrm{CdCl}_{2} \cdot 2.5 \mathrm{H}_{2} \mathrm{O}$ & & 4 & -80 & 0.969 \\
\hline S.major $-\mathrm{Zn}$ as $\mathrm{ZnSO}_{4} \cdot 7 \mathrm{H}_{2} \mathrm{O}$ & & 12 & $-1,000$ & 0.966 \\
\hline S.major $-\mathrm{Pb}$ as $\mathrm{Pb}\left(\mathrm{NO}_{3}\right)^{2}$ & & 4 & $-4,400$ & 0.986 \\
\hline S.major $-\mathrm{Fe}$ as $\mathrm{FeCl}_{3}$ & & 9 & -430 & 0.964 \\
\hline S.major $-\mathrm{Al}$ as $\mathrm{Al}_{2}\left(\mathrm{SO}_{4}\right)_{3} \cdot 18 \mathrm{H}_{2} \mathrm{O}$ & & 6 & $-6,700$ & 0.990 \\
\hline S.major $-\mathrm{Mn}$ as $\mathrm{MnSO}_{4} .5 \mathrm{H}_{2} \mathrm{O}$ & & 4 & $-2,600$ & 0.962 \\
\hline $\begin{array}{l}\text { S.major-Ni NiSO } 4.6 \mathrm{H}_{2} \mathrm{O} \\
\text { (Shuhaimi_Othman et al., 2011) }\end{array}$ & & 10 & $-25,000$ & 0.949 \\
\hline $\begin{array}{c}\text { Zooplanktons - Metalloid } \\
\text { D.magna - Se (Hoang et al., 2007) }\end{array}$ & 60 & 3 & -700 & 0.934 \\
\hline $\begin{array}{l}\text { Range } \\
\text { Average } \\
\text { Standard Deviation }\end{array}$ & & & $\begin{array}{c}-0.8 \text { to }-25,000 \\
-2,800 \\
6,500\end{array}$ & \\
\hline $\begin{array}{l}\text { Zooplanktons - Pesticide } \\
\text { C.vidua - Imidacloprid } \\
\text { (Sanchez-Bayo \& Goka, 2007) }\end{array}$ & 30 & 4 & $-2,400$ & 0.815 \\
\hline $\begin{array}{l}\text { D.magna - Imidacloprid } \\
\text { (Sanchez-Bayo, 2009) }\end{array}$ & 60 & 110 & $-2,100$ & 0.571 \\
\hline $\begin{array}{l}\text { G.pulex - Thialcoprid } \\
\text { (Beketov \& Liess, 2008) }\end{array}$ & 400 & 30 & $-11,000$ & 0.748 \\
\hline $\begin{array}{l}\text { G.pulex - Lindane } \\
\text { (Abel, 1980) }\end{array}$ & & 2 & -550 & 0.653 \\
\hline G.psuedolimaneus-Fenvalerate(A) & 500 & 6 & -0.07 & 0.983 \\
\hline $\begin{array}{l}\text { G.psuedolimaneus-Fenvalerate (J) } \\
\text { (Anderson R.L., 1982) }\end{array}$ & $\begin{array}{l}\text { (Bousfield, } \\
\text { 1958) }\end{array}$ & 4 & -0.24 & 0.928 \\
\hline $\begin{array}{l}\text { G.lacustris - Flucythrinate } \\
\text { (Anderson R.L., 1984) }\end{array}$ & $\begin{array}{l}500 \\
\text { (Wudkevich et } \\
\text { al., 1997) }\end{array}$ & 5 & -0.3 & 0.991 \\
\hline
\end{tabular}




\begin{tabular}{|l|c|c|c|c|}
\hline $\begin{array}{l}\text { A.salinus - Dimethoate** } \\
\text { (Parra et al., 2005) }\end{array}$ & & 5 & $-9,500$ & 0.994 \\
& \multicolumn{1}{|c|}{75} & 8 & $-2,500$ & 0.883 \\
$\begin{array}{l}\text { M.leuckarti-BHC } \\
\text { M.leuckarti-Fudaran } \\
\text { (Kurve et al., 2010) }\end{array}$ & (Vijvenberg, & 43 & $-1,200$ & 0.819 \\
\hline Range & $1980)$ & & & \\
Average & $30-500$ & 2 to 260 & -0.07 to $-11,000$ & \\
Standard Deviation & 240 & 50 & $-2,900$ & \\
& 200 & 80 & 4,000 & \\
\hline Total Slope & & & & \\
Range & & & -0.07 to $-11,000$ & \\
Average & & & 2,800 & \\
Standard Deviation & & & & \\
\hline
\end{tabular}

*calculated from $\ln \mathrm{NLT}_{\mathbf{5 0}}=\mathrm{b} / \mathrm{a}$, Equation 4. **Lifespan not available in literature. 
Table 2: Regression analysis of zooplankton toxicity data with a nonlinear relationship ${ }^{*}$

\begin{tabular}{|c|c|c|c|c|c|c|c|}
\hline $\begin{array}{c}\text { Zooplanktons } \\
\text { \&Toxicants }\end{array}$ & $\begin{array}{l}\text { Reported } \\
\text { NLT (d) }\end{array}$ & \multicolumn{2}{|c|}{$\begin{array}{l}\text { Calculated } \\
\text { NLT** }^{*}(d)\end{array}$} & \multicolumn{2}{|c|}{$\begin{array}{l}\text { Slope } \\
\text { (a) }\end{array}$} & \multicolumn{2}{|c|}{$\begin{array}{l}\text { Regression } \\
\text { Coefficient } \\
\qquad\left(\mathbf{R}^{2}\right)\end{array}$} \\
\hline Two Stage Model & & S-1 & $\mathrm{S}-2$ & S-1 & S-2 & S-1 & S-2 \\
\hline $\begin{array}{l}\text { Zooplanktons - Metals } \\
\text { D.magna - Zn }\end{array}$ & 60 & 3 & 620 & -700 & -40 & 0.999 & 0.999 \\
\hline $\begin{array}{l}\text { Zooplanktons - Pestcide } \\
\text { G. pulex - Thialcoprid }\end{array}$ & 400 & 8 & 70 & -4300 & -400 & 0.986 & 0.896 \\
\hline G. pulex-Lindane & 400 & 1 & 5 & -800 & -70 & 0.727 & 0.843 \\
\hline D. magna - Imidacloprid & 60 & 25 & 400 & -28000 & -600 & 0.892 & 0.882 \\
\hline $\begin{array}{l}\text { Range } \\
\text { Average } \\
\text { Standard deviation }\end{array}$ & $\begin{array}{c}60 \text { to } 400 \\
290 \\
210\end{array}$ & $\begin{array}{c}1 \text { to } 25 \\
10 \\
10\end{array}$ & $\begin{array}{c}5 \text { to } 620 \\
280 \\
290\end{array}$ & $\begin{array}{c}-700 \text { to }-28000 \\
-8500 \\
13000\end{array}$ & $\begin{array}{l}-40 \text { to }-600 \\
-280 \\
280\end{array}$ & & \\
\hline
\end{tabular}

*nonlinear correlation coefficient $\left(R^{2}\right)<0.8 * *$ calculated from $\ln \mathrm{NLT}_{\mathbf{5 0}}=\mathrm{b} / \mathrm{a}$, Equation $4 . * * *$ Term S-1 and S-2 are used for Stage- 1 and Stage- 2 of the two stage model respectively. 
Table 3 Regression analysis results obtained for fish with metals and pesticides (Verma et al., 2011).

\begin{tabular}{|l|c|c|c|}
\hline \multicolumn{1}{|c|}{ Fish } & Range & Average & STD \\
\hline Slope - Organic compounds & -0.42 to $-210,000$ & $-33,000$ & 68,000 \\
Slope - Metals & -34 to $-42,000$ & $-13,300$ & 13,700 \\
Slope Total & -0.42 to $-210,000$ & $-21,000$ & 44,000 \\
Reported NLT & 360 to 2,600 & 1,300 & 800 \\
Calculated NLT & 3.6 to 5,000 & 300 & 1,100 \\
$\mathrm{R}^{2}$ & 0.834 to 0.999 & & \\
\hline
\end{tabular}




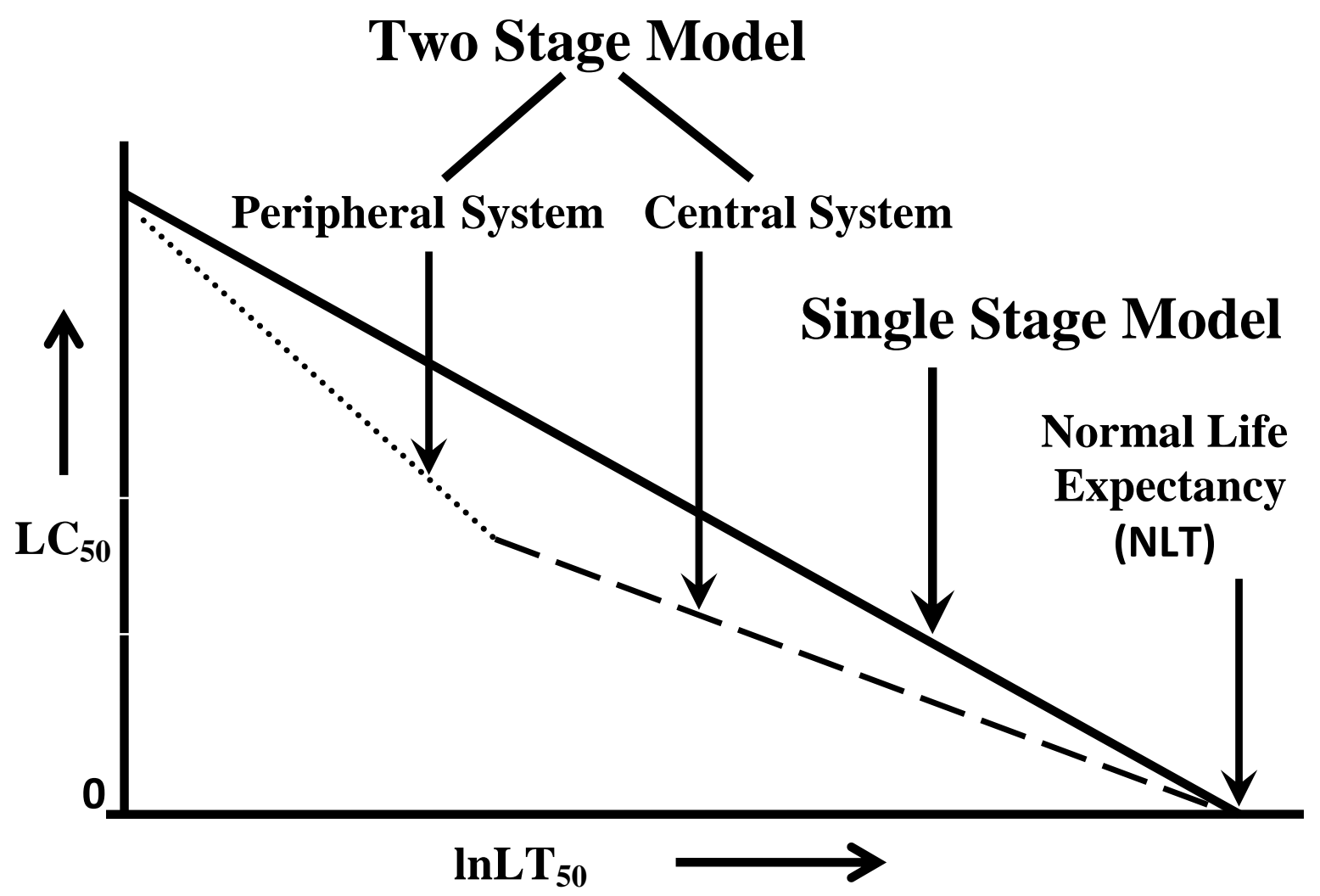

Figure 1: Model showing conceptual relationship between $\mathrm{LC}_{50}$ and exposure time for a single stage and a two stage RLE model with central and peripheral system. 


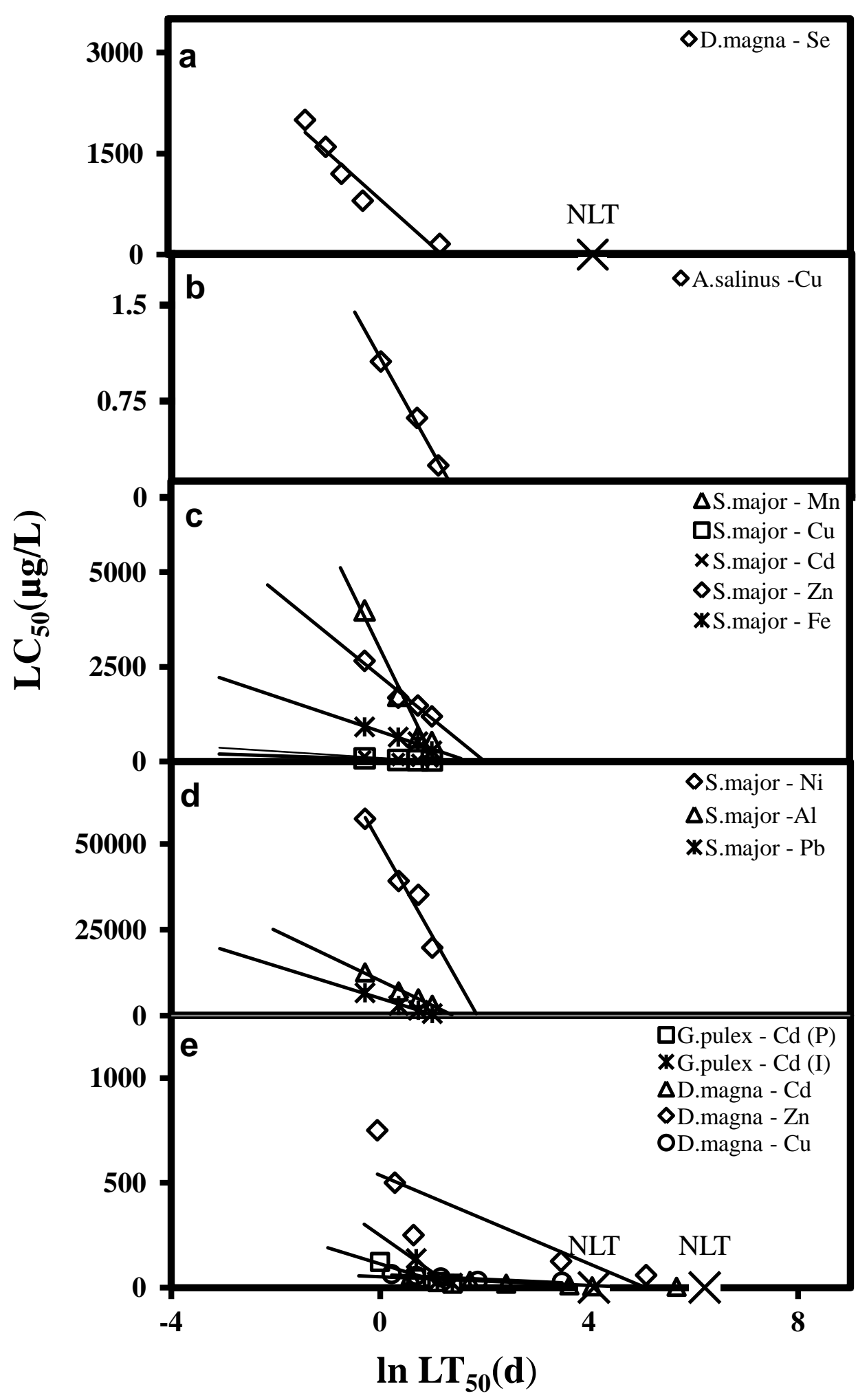

Figure 2: Plots of $L C_{50}$ versus $\ln L T_{50}$ for zooplanktons with linear regression lines for metalloid (a) and metal (b, c, d, e) data sets. Normal life expectancy (NLT) is indicated, where one cross on the $\mathrm{x}$-axis represents average of reported NLT values when only one species of zooplankton is involved. When more than one species are involved two crosses represent range of NLT between lowest and highest average NLT. *S.major and A.salinus lifespan is not available in literature. 


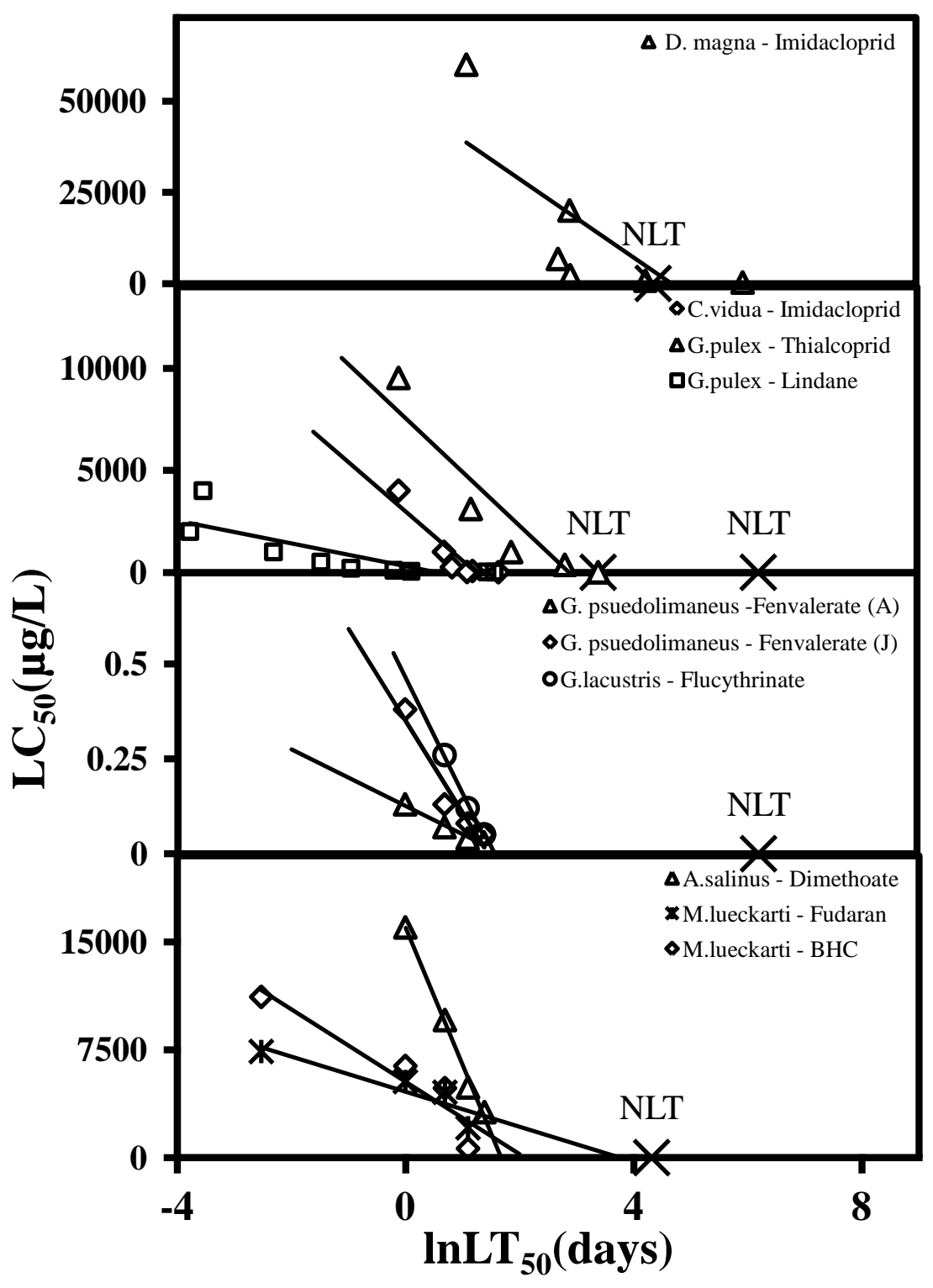

Figure 3: Plots of $L C_{50}$ versus $\ln L T_{50}$ for zooplanktons with linear regression lines with pesticides with normal life expectancy shown. One cross on $\mathrm{x}$-axis represents average reported NLT where only one species of zooplanktons is involved. When more than one species are involved two crosses represent range of NLT between lowest and highest average NLT. 


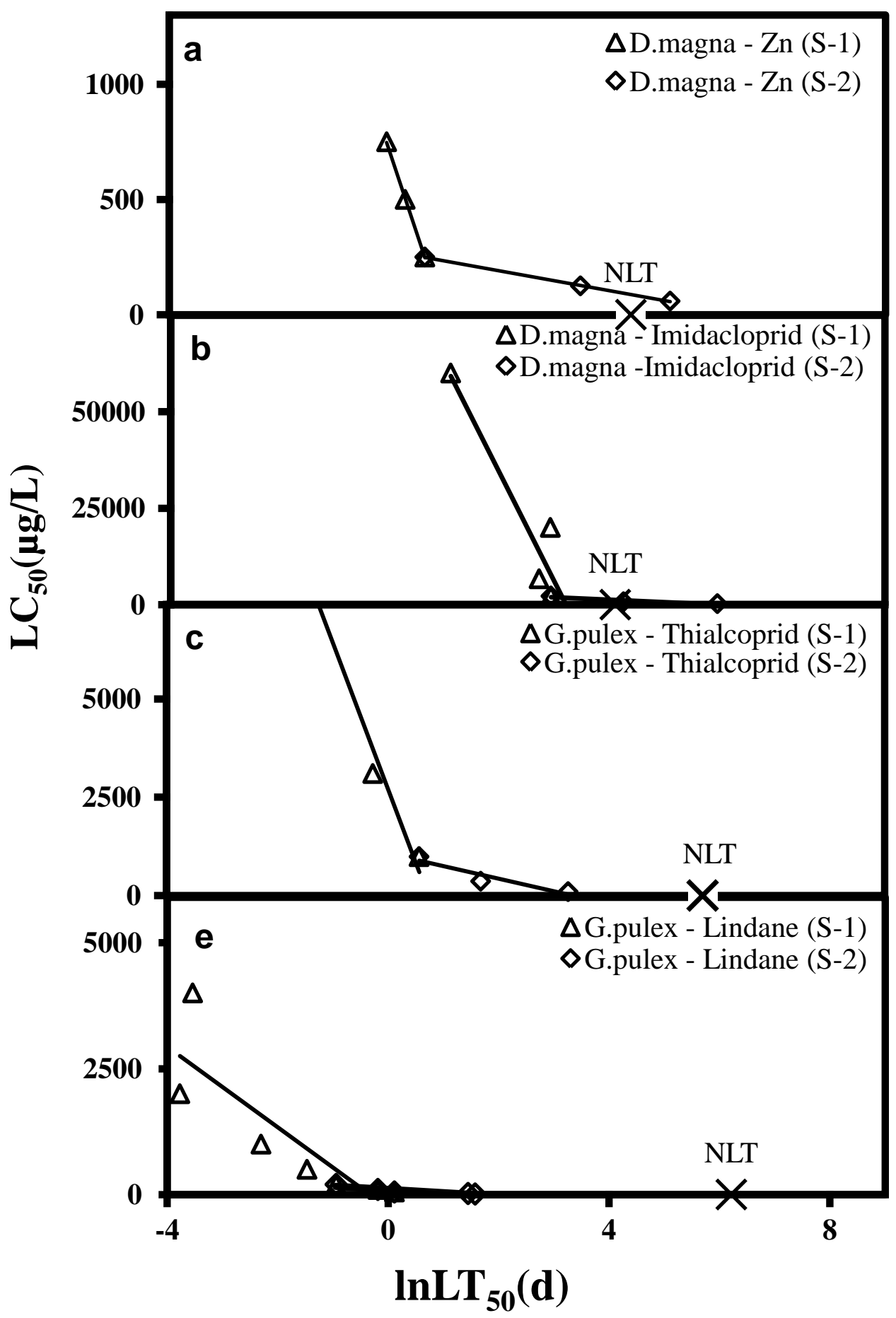

Figure 4: Plots of $L C_{50}$ versus $\ln L T_{50}$ for zooplanktons with linear regression lines using the two stage RLE model. One cross on the x-axis represents average reported NLT where only one species of zooplankton is involved. When more than one species are involved two crosses represent range of NLT between lowest and highest average NLT. 